\title{
The cold pressor test: Vascular and myocardial response patterns and their stability
}

\author{
PATRICE G. SAAB, MARIA M. LLABRE, BARRY E. HURWITZ, \\ NEIL SCHNEIDERMAN, WILLIAM WOHLGEMUTH, \\ LYNN A. DUREL, CLIFFORD MASSIE, AND JOACHIM NAGEL \\ Department of Psychology, University of Miami, Coral Gables, FL
}

\begin{abstract}
The purposes of the present study were to compare the cardiovascular response patterns evoked by three versions of the cold pressor test (either forehead stimulation or hand or foot immersion) and to determine the reproducibility of the responses over a 2 -week interval. Blood pressure, heart rate, stroke volume, cardiac output, total peripheral resistance, and systolic time intervals were obtained during rest and during the cold pressor test in 42 young men. Across conditions, the pressor response was supported by peripheral resistance increases with concomitant stroke volume decreases. Although the response patterns were generally similar across sites, exceptions were apparent for heart rate. Forehead stimulation was characterized by no significant change in heart rate, whereas limb (hand or foot) immersion was associated with significant heart rate acceleration. The responses elicited by the three cold pressor test conditions were reliable and showed little evidence of attenuation over the test-retest interval.
\end{abstract}

Descriptors: Cold pressor test, Impedance cardiography, Total peripheral resistance, Cardiac output, Systolic time intervals, Generalizability

The cold pressor test has a long history of use in cardiovascular research (e.g., Hines \& Brown, 1936). It has been postulated generally that the cold pressor test constitutes a largely alphaadrenergic challenge, evoking marked vasoconstriction (Abboud \& Eckstein, 1966; Lovallo, 1975; Schneiderman \& McCabe, 1989). Although contradictory evidence is available (e.g., Armstrong \& Rafferty, 1950; Eich \& Jacobsen, 1967; Harlan, Osborne, \& Graybiel, 1964; Thacker, 1940), blood pressure (BP) hyperresponsivity to the cold pressor test has been related to the eventual development of hypertension (e.g., Menkes et al., 1989; Wood, Sheps, Elveback, \& Schirger, 1984) and coronary heart disease (Keys et al., 1971). Recent work has shown that the cold pressor test is also a useful tool in evoking hemodynamic differences between blacks and whites, groups with differential risks of hypertension (e.g., Anderson, Lane, Muranaka, Williams, \& Houseworth, 1988; Tischenkel et al., 1989). The association of the cold pressor test with disease end points and the capacity of this test to distinguish among risk groups, in part, accounts for the continued interest in this challenge.

This work was supported by Research Grants HL31648 and HL36588 and Research Training Grant HL07426 - all from the National Heart, Lung and Blood Institute of the National Institutes of Health.

Address reprint requests to: Dr. Patrice G. Saab, Behavioral Medicine Research Center, Department of Psychology, University of Miami, P.O. Box 248185, Coral Gables, FL 33124.
With the widespread use of the cold pressor test, multiple procedures for its implementation have been reported, including immersing a hand (e.g., Hines, 1940; Menkes et al., 1989) or a foot (e.g., Light, Obrist, Sherwood, James, \& Strogatz, 1987; Saab et al., 1991) in an ice bath or applying a cold pack to the forehead region (Abboud \& Eckstein, 1966; Anderson et al., 1988; Durel et al., 1993; Khurana, Watabiki, Hebel, Toro, \& Nelson, 1980; Peckerman et al., 1991). ${ }^{1}$ Task lengths have also varied across studies (e.g., Garwood, Engel, \& Capriotti, 1982; Stratton, Holter, Hallstrom, Caldwell, \& Ritchie, 1983), and posture has been either supine (e.g., Abboud \& Eckstein, 1966; Durel et al., in press; Hines \& Brown, 1936) or sitting (Durel et al., 1993; Light et al., 1987; Saab et al., 1991). These procedural differences across laboratories have made it difficult to draw firm conclusions about task equivalence.

This practice of using the versions of the cold pressor test interchangeably demands a direct comparison of the responses evoked by the three procedures. A demonstration of equivalence necessitates systematically comparing the three procedures with a consistent set of cardiovascular indices, not limited to BP and heart rate (HR). Impedance cardiography allows a more com-

'Although Khurana et al. (1980) referred to this application as the cold face test, it will be referred to as forehead stimulation throughout our paper, following Abboud and Eckstein's (1966) and Anderson et al.'s (1988) actual description of the procedures. 
prehensive assessment of cardiovascular functions. Although impedance cardiography has been implemented in individual studies of forehead cold stimulation (e.g., Musante, Treiber, Strong, \& Levy, 1990; Saab et al., 1992; Treiber et al., 1990), hand immersion (e.g., Allen \& Crowell, 1989; Fahrenberg, Schneider, \& Safian, 1987; McKinney et al., 1985; Myrtek, 1985), and foot immersion (e.g., Sherwood, Allen, Obrist, \& Langer, 1986), the same parameters have not necessarily been examined or compared in a single study.

The temporal stability of the three versions has also not been compared. The merit of studying cardiovascular responsivity to the cold pressor as a marker for hypertensive risk and as a potential means for understanding group differences depends in part on a demonstration of the temporal stability of the cold pressor test. This information is essential in determining whether response patterns elicited by forehead stimulation and by foot or hand immersion are equally stable.

Information from separate studies shows that although delta scores for HR, systolic (S) BP, and diastolic (D) BP responses have sometimes been reported as reliable across repeated assessments, correlations have fluctuated markedly across studies, with ranges of $.12-.90, .25-.75$, and .19-.87 for each respective measure (Allen, Sherwood, Obrist, Crowell, \& Grange, 1987; Arena, Blanchard, Andrasik, Cotch, \& Myers, 1983; Durel et al., 1993; Fahrenberg et al., 1987; Faulstich et al., 1986; Lacey \& Lacey, 1962; McKinney et al., 1985; Myrtek, 1985; Peckerman et al., 1991; Saab et al., 1992; Van Egeren \& Sparrow, 1989). Of the four studies to date that have examined the stability of impedance cardiography-derived responses to a cold pressor test, three used hand immersion (Fahrenberg et al., 1987; McKinney et al., 1985; Myrtek, 1985) and one study used forehead stimulation (Saab et al., 1992). Across studies, the reliability of cardiac output $(\dot{Q})$ and Heather Index $(\mathrm{HI})$ declined with longer intervals (Fahrenberg et al., 1987; McKinney et al., 1985; Myrtek, 1985; Saab et al., 1992). In contrast, for studies that reported stroke volume (SV), responses remained moderately stable over 1 week to 3 months (McKinney et al., 1985; Myrtek, 1985; Saab et al., 1992), whereas total peripheral resistance (TPR) responses, reported in only two studies (McKinney et al., 1985; Saab et al., 1992), were unreliable (.02 and .14). In light of the relative absence of standards in the application of impedance cardiography, these data suggest that it is prudent to demonstrate short-term stability prior to discussion of long-term stability.

The present study had two goals: to compare directly the cardiovascular responses evoked by the three cold pressor test challenges and to determine the temporal stability of the response patterns evoked by the three versions. To this end, BP, HR, SV, $\dot{Q}$, TPR, as well as the $\mathrm{HI}$ and the ratio of the preejection period to left ventricular ejection time (PEP/LVET) were measured in normotensive white men who had been randomly assigned to one of three cold pressor test conditions: (a) forehead stimulation, (b) hand immersion, or (c) foot immersion. The stability of the responses evoked by each condition was determined over a 2 -week test-retest interval.

\section{Methods}

\section{Subjects}

Forty-two healthy normotensive white men, ranging in age from 18 to 22 years, participated in this study. Eligibility required that subjects had not previously participated in laboratory BP stud-
Table 1. Characteristics of Subjects in Each Cold Pressor Test Group

\begin{tabular}{|c|c|c|c|}
\hline \multirow{3}{*}{$\begin{array}{c}\begin{array}{c}\text { Subject } \\
\text { characteristics }^{a}\end{array} \\
\text { Casual SBP }(\mathrm{mmHg})\end{array}$} & \multicolumn{3}{|c|}{ Test group } \\
\hline & Head & Hand & Foot \\
\hline & $(9.8)$ & $(9.7)$ & $121 \quad(9.2)$ \\
\hline Casual DBP (mmHg) & $67 \quad(11.4)$ & $67 \quad(10.4)$ & $70 \quad(8.1)$ \\
\hline Age (years) & $18.6(1.2)$ & $19.1(1.1)$ & $19.1(0.8)$ \\
\hline $\mathrm{BMI}\left(\mathrm{kg} / \mathrm{m}^{2}\right)$ & $23.9 \quad(2.5)$ & $22.3 \quad(2.7)$ & $26.1(4.0)$ \\
\hline $\begin{array}{l}\text { Frequency of parental } \\
\text { hypertension }\end{array}$ & 3 & 2 & 3 \\
\hline
\end{tabular}

Note: Values are means $(S D)$ or frequency where indicated. ${ }^{a} \mathrm{SBP}=$ systolic blood pressure; DBP $=$ diastolic blood pressure; $\mathrm{BMI}=$ body mass index.

ies and had no current or past history of the following conditions: heart disease, diabetes, hypertension, renal disease, rheumatic fever, seizure disorder, hemophilia, or hepatitis. All subjects were required to be free from medications with known cardiovascular effects. Casual BP and demographic characteristics are displayed in Table 1 . With the exception of body mass index $(\mathrm{BMI})(F[2,39]=5.04, p<.01)$, casual BP and demographic characteristics were similar across the cold pressor conditions. Significant differences in BMI emerged only for foot immersion relative to hand immersion.

Upon completion, participants received \$15 and credit toward partial fulfillment of requirements in an introductory psychology course.

\section{Procedures}

Each subject came to the laboratory for three visits: (a) the assessment day, (b) laboratory Session 1, and (c) laboratory Session 2. During the assessment day, the experimenter described the nature of the study, and written informed consent was obtained. In addition, mercury sphygmomanometer assessments of BP status, personal and family medical history, and habits were made to determine eligibility. If eligible, the subject was scheduled for two laboratory sessions made for the same time of day but held 2 weeks apart. The subject was instructed to abstain from all sources of caffeine, nicotine, and alcohol for $2 \mathrm{hr}$, drug usage for $24 \mathrm{hr}$, and exercise for $2 \mathrm{hr}$ prior to his next appointment.

Prior to Session 1, the subjects were randomly assigned to one of three experimental conditions: (a) forehead cold stimulation, (b) hand immersion cold pressor, or (c) foot immersion cold pressor.

\section{Laboratory Sessions}

Upon arrival for Session 1, compliance with restrictions regarding substance and activity was determined. If compliance was satisfactory, an overview of the procedures was provided. Weight, height, and hematocrit (via finger stick while semireclined) determinations were made prior to application of the transducers.

While the subject stood at full stature, the impedance cardiograph electrode tape (\#M6001, Label Technologies; mylar backed aluminum) was affixed to the neck and the chest in full band configuration to record $Z_{0}$ (basal thoracic impedance in ohms) and $d Z / d t$ (the first derivative of the change in imped- 
ance). Electrocardiograph (ECG) electrodes were then applied to the chest, and a strain gauge was taped to the abdomen to record respiration. Lastly, a phonocardiogram transducer (Fukaida Denshi Co.) was placed over the second or fourth intercostal space just to the left of the sternum to record the first and second heart sounds (for further detail regarding transducer application please refer to Saab et al., 1992). At Session 1, the sensitivity and filter settings and the distances between the transducer placements were recorded so they could be reproduced at Session 2.

The subject was then seated in a lounge chair (angled at $45^{\circ}$ ) such that a semireclined posture was maintained throughout the session. The right foot was supported on the lounge, and the left foot rested flat on the floor. Both arms rested on tables and were supported at heart level.

The automated BP cuff was attached to the right arm. Then the electrode distance $(L)$ in $\mathrm{cm}$ between $Z_{2}$ and $Z_{3}$ (the two inner bands of the tetrapolar configuration used to record $Z_{0}$ and $d Z / d t$ ) was measured. When the subject was comfortable, the experimenter oriented him to the forthcoming procedures and briefly described the cold pressor condition that he would receive. The experimenter remained with the subject throughout the rest of the session to deliver instructions. A 20-min resting baseline preceded the cold pressor test. The BP measures were initiated at $0.25 \mathrm{~min}, 1.75 \mathrm{~min}, 3.25 \mathrm{~min}, 4.75 \mathrm{~min}, 10 \mathrm{~min}$, $15 \mathrm{~min}, 16.5 \mathrm{~min}, 18 \mathrm{~min}$, and $19.5 \mathrm{~min}$ into the rest period.

Upon termination of the pretask rest period, the cold pressor stimulus was brought into the subject's room, and specific task instructions were given. The cold pressor test (see below) lasted $100 \mathrm{~s}$. Two BP readings taken during this interval were initiated at $5 \mathrm{~s}$ and $55 \mathrm{~s}$. Immediately upon termination of the cold pressor test, the posttask resting period ensued. The procedure for sampling BP was identical to that of the pretask resting baseline. Upon completion of the rest period, the automated BP cuff was removed, and a second finger-stick for hematocrit determinations was made. Next, the transducers were detached and the subject was given instructions for the next session regarding substance and activity restrictions. The subject was also requested not to make major habit changes prior to Session 2 .

Procedures for Session 1 and for Session 2 were identical. Both sessions were held at the same time of day and were staffed by the same experimenters to control for possible circadian and differential social influences. At the end of the Session 2 visit, the subject was debriefed, thanked, and compensated for his participation.

\section{Tasks}

The same cold pressor test was presented to the subject at both sessions.

Forehead cold stimulation. The stimulus for the forehead cold stimulation condition consisted of a pliable plastic bag containing a $4{ }^{\circ} \mathrm{C}$ mixture of crushed ice $(4.5$ cups $[1.08 \mathrm{~L}])$ and water $(0.5$ cup $[120 \mathrm{ml}])$. During the task, the experimenter stood behind the subject and securely held the bag with both hands so that it covered the subject's forehead (above the brow line) and temple region.

Hand immersion. The stimulus for the hand immersion condition consisted of a $4{ }^{\circ} \mathrm{C}$ icebath. The icebath was comprised of 1 gallon $(3.8 \mathrm{~L})$ of water and four standard trays of ice in a $12.5-\times 8.5-\times 5$-in. $(31.75-\times 21.59-\times 12.7-\mathrm{cm})$ plastic pan. A portion of the table top on which the subject's left arm rested was removed to permit the pan to be placed on an inner shelf of the table. This apparatus was designed to minimize any upper body movement associated with the task. When instructed, the subject immersed his hand in the icebath so that it lay flat against the bottom. After $100 \mathrm{~s}$, the limb was removed from the bath, the table top was replaced, and the experimenter immediately wrapped and resituated the subject's arm.

Foot immersion. The same stimulus used for the hand condition was employed in the foot condition. During instructions the left foot rested on the edge of the pan. At task onset, the subject submerged his foot so that it rested on the bottom of the pan. When the task was complete, the subject withdrew his foot from the pan and placed it on the towel on the floor; the foot was dried by the experimenter.

\section{Physiological Measures}

A Critikon Dinamap Vital Signs Monitor (Model 1846 SX) is an oscillometric device, which was used to measure SBP, DBP, and mean arterial pressure (MAP). The ECG, phonocardiogram, $d Z / d t$, and respiration were displayed continuously on the Grass polygraph (Model 7D) to monitor signal quality. The respiration data were used to ensure that the subject did not hold his breath during the procedures. With the exception of $d Z / d t$ and $Z_{0}$, the signals were relayed from the polygraph to an $\mathrm{A} / \mathrm{D}$ converter (DT2821) sampling at $1 \mathrm{kHz}$ per channel and were stored in an IBM PC-AT computer. The $d Z / d t$ and $Z_{0}$ signals were relayed directly from a Minnesota Impedance Cardiograph (Model 304B) to the A/D converter so that the impedance signal would be free of the attenuating effects imposed by the high-frequency filtering of the polygraph. The $d Z / d t$ and $Z_{0}$ calibration signals were also stored in the computer for later conversion of the $d Z / d t$ to ohms/s and SV derivation.

The data were collected in 30-s epochs during the rest periods and during the task periods (see Data Reduction section for the sampling schedule). These samples were ensemble averaged by a computer program that summed the digitized beat-by-beat waveforms, time synchronized to the R-wave of the ECG, and divided by the number of cardiac cycles. The ensemble average was then graphically displayed, and the waveform events were scored by computer signal processing techniques and manually confirmed by an operator. The precision of the computer software for detecting the signal events has been previously described elsewhere (see Nagel et al., 1989). Rationale for the event detection and parameter estimation are provided by Nagel et al. (1989) and Saab et al. (1992). The signal events detected by the signal processing program follow (a) ECG Q-wave onset, (b) ECG R-wave, (c) the end of the ECG T-wave, (d) the onset of the second heart sound, (e) the $d Z / d t$ B-wave, (f) the peak of the $d Z / d t$, and $(\mathrm{g})$ the $d Z / d t \mathrm{X}$-wave onset.

The following indices of cardiovascular performance were also derived: (a) HR (bpm), (b) HI $\left(\mathrm{ohm} / \mathrm{s}^{2}\right)$, (c) PEP (ms), (d) LVET (ms), and (e) SV (ml). Stroke volume was calculated using the Kubicek formula (Kubicek, Witsoe, Patterson, \& From, 1969). For this equation, rho (blood resistivity in ohms/ $\mathrm{cm}$ ) was calculated as $\rho=53.2 \mathrm{e}^{(0.022) \mathrm{Hct}}$. The hematocrit value in the equation is the mean of two values obtained during the first finger stick. The values from the second finger stick were used to confirm that the initial values were within range. Cardiac output ( $\mathrm{L} / \mathrm{min})$ and TPR (peripheral resistance units [pru]), measured by dividing the ratio of $\mathrm{MAP} / Q$ by 16.67 (Guyton, 1981), were also derived. 
Table 2. Baseline and Task Cardiac Values for Each Cold Pressor Test Condition

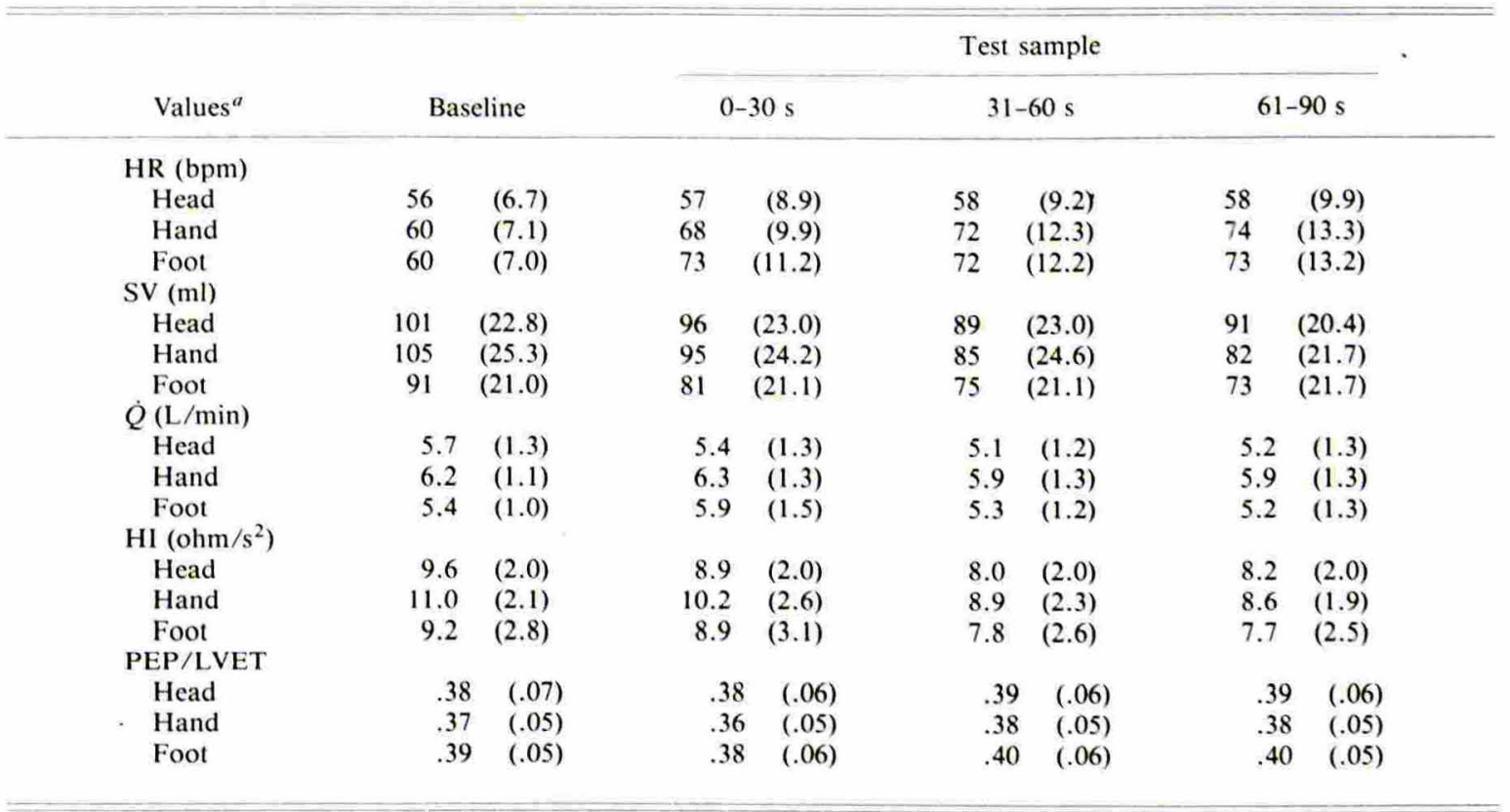

Note: Values are means $(S D)$.

${ }^{a} \mathrm{HR}=$ heart rate; $\mathrm{SV}=$ stroke volume; $\dot{Q}=$ cardiac output $; \mathrm{HI}=$ Heather Index; PEP $/ \mathrm{LVET}=$ preejection period $/$ left ventricular ejection time.

\section{Data Reduction}

For the analyses that follow, the resting pretask baseline samples were initiated at $15 \mathrm{~min}, 16.5 \mathrm{~min}, 18 \mathrm{~min}$, and $19.5 \mathrm{~min}$, and the cold pressor test samples were initiated at $0 \mathrm{~s}, 31 \mathrm{~s}$, and $61 \mathrm{~s}$. Mean values were calculated for all pretask baseline measures by averaging four samples, initiated at $15 \mathrm{~min}, 16.5 \mathrm{~min}$, $18 \mathrm{~min}$, and $19.5 \mathrm{~min}$ into the pretask rest period. To obtain baseline TPR, the 30-s $\dot{Q}$ samples were matched with the MAP sample that began at the same time. For task TPR, the 30-s $\dot{Q}$ samples that started at $0 \mathrm{~s}$ and at $61 \mathrm{~s}$ were matched with the MAP measurement that occurred closest in time, that is, those initiated at $5 \mathrm{~s}$ and at $55 \mathrm{~s}$, respectively.

\section{Results}

The design used in this study was a condition by period splitplot factorial, with condition (three levels: forehead, hand, and foot) as a between subjects factor and period (two, three, or four levels, depending on the dependent variable: baseline and respective task period values) as a within-subjects factor. Data were collected under this design at two sessions, scheduled 2 weeks apart. The session factor was conceptualized as a replication and included in the design to assess the stability of responses to the cold pressor test over time (see section on Reliability of Responses). To compare response patterns of the three versions of the cold pressor test, responses were averaged across sessions. Means and standard deviations are presented in Tables 2 and $\mathbf{3}$ by condition for each period and dependent measure.

\section{Session Comparisons}

Preliminary analyses of variance (ANOVAs), including session as a second within-subjects factor, were conducted to assess session main effects (also measured with the generalizability analyses) and interactions. Given the number of dependent variables studied in the session comparisons, these inferential tests were performed at the .01 level. The results of these preliminary analyses revealed no significant session main effects and no Session $\times$ Condition or Session $\times$ Condition $\times$ Period interactions. A significant Session $\times$ Period interaction was observed for HR $(F[3,117]=8.73, p<.001)$. The means for Session 1 were 58 , 64,66 , and 68 bpm for baseline and the three cold pressor sampling periods, respectively. Slightly higher values were observed at Session 2 at baseline ( $60 \mathrm{bpm})$ and during the first two cold pressor periods $(68,69 \mathrm{bpm})$ but not during the last $30 \mathrm{~s}$ of the cold pressor test.

\section{Cold Pressor Test Conditions, Combined Across Sessions}

A Condition $\times$ Period interaction (after combining the data from the two sessions) was obtained with respect to $\operatorname{HR}(F[4,77]=$ $7.11, p<.01) .^{2}$ Post hoc analyses were completed with Tukey's HSD for each cold pressor condition, separately. The results indicated a lack of HR response to the forehead cold pressor test (Table 2). However, there were significant differences in response to the foot immersion cold pressor test between the baseline and the three task periods $(0-30 \mathrm{~s}, 31-60 \mathrm{~s}$, and 61-90s) and significant differences in response to the hand cold pressor test between the baseline and the last two cold pressor periods. There was also a significant difference between the first and last cold pressor periods in the hand immersion condition. A condition

${ }^{2}$ Degrees of freedom reflect a correction for lack of sphericity using the Huyhn-Feldt procedure. 
main effect was also only observed in $\operatorname{HR}(F[2,39]=7.34$, $p=.002$ ). Across periods, HR for the hand and foot cold pressor conditions were significantly greater than those for the forehead condition. ${ }^{3}$

All dependent measures except PEP/LVET exhibited significant period effects at the .01 level or less. The $F$ values ranged from 12.13 for $Q$ to 104.46 for SBP. The overall pattern was one of steady increases in BP and TPR and decreases in SV, $Q$, and $\mathrm{HI}$ from baseline through the duration of the task (see Tables 2 and 3). With the exception of HR (see above), the post hoc analyses for all other period main effects were completed using Tukey's HSD on the total sample means at the .01 level. The results indicated significant differences among all three periods (baseline, $5 \mathrm{~s}$, and $55 \mathrm{~s}$ ) for SBP, DBP, and TPR, with all three measures showing a steady increase from baseline. For SV, the baseline value was significantly different from those of all cold pressor sample periods. The values for the last two periods were similar to each other, and the value from the first cold pressor period was significantly different from that from the last. Pairwise differences were not detectable in $Q$ using Tukey's HSD procedure. With respect to $\mathrm{HI}$, the baseline value was similar to that of the first cold pressor period and significantly different from those of the last two cold pressor periods, whose values were similar to each other, suggesting that beta-adrenergic drive to the myocardium decreased over the course of the cold

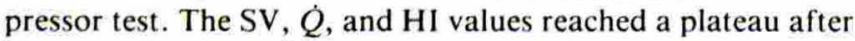
the second task reading (see Table 2) within $65 \mathrm{~s}$.

Estimates of the strength of association using $\omega^{2}$ (Hays, 1988) were calculated for each significant period effect. The period explained $38 \%$ and $33 \%$ of the variance in SBP and DBP, respectively. Variance explained by period was $17 \%$ for TPR but only $2 \%, 2.5 \%$, and $<1 \%$ for SV, HI, and $Q$, respectively. Because there was a significant Condition $\times$ Period interaction for HR, $\omega^{2}$ was computed for each significant condition separately. The period explained $17 \%$ and $19 \%$ of the variance in HR for the hand and foot conditions, respectively.

\section{Reliability of Cold Pressor Responses}

Stability of BP, HR, SV, $\dot{Q}$, TPR, HI, and PEP/LVET measures was assessed over a 2-week interval using generalizability procedures. These procedures were described by Cronbach, Glaser, Nanda, and Rajaratnam (1972), and their application to physiological data was illustrated by Llabre et al. (1988) and Saab et al. (1992). Table 4 includes the results of the generalizability $(G)$ coefficients and the dependability $\left(G^{*}\right)$ coefficients $\left(G^{*}\right.$ is in parentheses whenever it is different from $\left.G\right) .{ }^{4}$ Base-

\footnotetext{
${ }^{3}$ We examined the pattern of correlations between BMI and the HR responses because significant condition differences had been obtained for HR only. The pattern of correlations were inconsistent across the conditions, and none of the correlations were significant. Furthermore, the direction of condition differences in BMI did not correspond to the condition differences in HR. Therefore, cold pressor condition HR differences cannot be attributed to differences in BMI.

${ }^{4}$ The first line of data for each variable represents the generalizability based on one session. The intraclass correlation formula was used to project how generalizability is expected to increase if, instead, readings from two sessions were combined. These are shown on the second line. When only one source of random error variance is considered, the $G$ is like the conventional reliability estimate (Pearson $r$ ). The distinction between $G$ and $G^{*}$ is that the $G^{*}$ incorporates into the error term not only random error but also systematic level differences between conditions.
}

Table 3. Baseline and Task Blood Pressure and TPR Levels for Each Cold Pressor Test Condition

\begin{tabular}{|c|c|c|c|c|c|c|}
\hline \multirow[b]{2}{*}{ Values $^{a}$} & \multirow{2}{*}{\multicolumn{2}{|c|}{ Baseline }} & \multicolumn{4}{|c|}{ Test sample } \\
\hline & & & \multicolumn{2}{|c|}{$5-30 \mathrm{~s}$} & \multicolumn{2}{|c|}{$55-80 \mathrm{~s}$} \\
\hline \multicolumn{7}{|c|}{$\mathrm{SBP}(\mathrm{mmHg})$} \\
\hline Head & 112 & $(6.7)$ & 123 & $(10.6)$ & 137 & $(17.2)$ \\
\hline Hand & 108 & $(8.2)$ & 117 & (12.9) & 134 & $(14.0)$ \\
\hline Foot & 112 & $(6.2)$ & 123 & $(9.9)$ & 138 & $(17.0)$ \\
\hline \multicolumn{7}{|c|}{ DBP $(\mathrm{mmHg})$} \\
\hline Head & 57 & (6.0) & 72 & (13.1) & 74 & $(14.0)$ \\
\hline Hand & 57 & $(3.0)$ & 68 & $(8.4)$ & 78 & $(10.3)$ \\
\hline Foot & 60 & $(7.2)$ & 72 & (11.1) & 79 & $(14.1)$ \\
\hline \multicolumn{7}{|l|}{ TPR (pru) } \\
\hline Head & & $7(0.18)$ & 1.09 & $(0.31)$ & 1.25 & $(0.43)$ \\
\hline Hand & & $6(0.16)$ & 0.87 & $(0.25)$ & 1.09 & $(0.33)$ \\
\hline Foot & & $2(0.20)$ & 1.00 & $(0.23)$ & 1.26 & $(0.32)$ \\
\hline
\end{tabular}

Note: Values are means $(S D)$.

${ }^{a} \mathrm{SBP}=$ systolic blood pressure $; \mathrm{DBP}=$ diastolic blood pressure; $\mathrm{TPR}=$ total peripheral resistance.

line stability results replicated those reported in Saab et al. (1992). Results of the reliability of both task levels and deltas are also presented in Table $\mathbf{4}$ for each cold pressor condition. The task levels used in these analyses were based on values for the last period of the task for SBP, DBP, and TPR or the mean of the values for the last two periods of the task for all other measures. ${ }^{5}$ Session differences resulted only in slight decreases in dependability of HR, $Q$, and TPR, primarily in the hand condition. Deltas were calculated by subtracting the mean of the baseline from the mean of the task levels. The coefficients for task levels and those associated with the deltas indicate that reactivity to the cold pressor can be reliably assessed over a 2-week interval.

\section{Discussion}

In the present study, the cardiovascular response patterns and the reproducibility of three versions of the cold pressor test were comprehensively assessed. This is the first study to compare systematically the three versions of the cold pressor test. All versions elevated SBP and DBP over resting levels. Across all conditions, the pressor response was supported by increases in TPR; concomitant decreases were observed in SV. Heart rate showed an increase for hand and for foot immersion and showed no reliable change for forehead stimulation. Previous research demonstrated that a HR deceleration usually occurs with forehead stimulation (e.g., Khurana et al., 1980). Cold stimulation of the ophthalmic trigeminal dermatome evokes marked parasympathetic, in addition to sympathetic, activation (Abboud \& Eckstein, 1966). The absence of a HR increase with forehead stimulation is consistent with augmented vagal restraint reputed to be characteristic of the diving reflex. The time dependent (PEP/LVET) and volume dependent (HI) systolic time interval responses during all three tasks did not provide evidence consistent with increased beta-adrenergic drive on the myocardium.

\footnotetext{
${ }^{5}$ When reliability analyses were repeated using the average of all available task readings, the results were identical to those presented.
} 
Table 4. Generalizability Coefficients ( $G$ and $\left.G^{*}\right)$ for Assessing 2-Week Cold Pressor Test Stability Measures

\begin{tabular}{|c|c|c|c|c|c|c|c|c|}
\hline \multirow[b]{2}{*}{ Measure $^{a}$} & \multirow{2}{*}{$\begin{array}{l}\text { Number of } \\
\text { sessions }\end{array}$} & \multirow{2}{*}{$\begin{array}{l}\text { Baseline } \\
(n=42)\end{array}$} & \multicolumn{3}{|c|}{$\begin{array}{c}\text { Task } \\
(n=14)\end{array}$} & \multicolumn{3}{|c|}{$\begin{array}{c}\text { Delta } \\
(n=14)\end{array}$} \\
\hline & & & Head & Hand & Foot & Head & Hand & Foot \\
\hline \multirow[t]{2}{*}{ HR } & 1 & .82 & .81 & $.91(.88)$ & .92 & .62 & $.90(.86)$ & $.88(.83)$ \\
\hline & 2 & .90 & .90 & $.95(.94)$ & .96 & .77 & $.95(.92)$ & $.94(.91)$ \\
\hline \multirow[t]{2}{*}{$\dot{Q}$} & 1 & .74 & .69 & $.71(.67)$ & .83 & $.59(.58)$ & $.39(.37)$ & .90 \\
\hline & 2 & .85 & .82 & $.83(.80)$ & .91 & $.74(.73)$ & $.57(.54)$ & .95 \\
\hline \multirow[t]{2}{*}{ SV } & 1 & .86 & .87 & .78 & .87 & .51 & .53 & .91 \\
\hline & 2 & .92 & .93 & .88 & .93 & .68 & .69 & .95 \\
\hline \multirow[t]{2}{*}{$\mathrm{HI}$} & 1 & .87 & .82 & .75 & .91 & .69 & .47 & .89 \\
\hline & 2 & .93 & .90 & .86 & .96 & .82 & .64 & .94 \\
\hline \multirow[t]{2}{*}{ PEP/LVET } & 1 & .84 & .82 & .66 & .70 & .47 & .26 & .50 \\
\hline & 2 & .91 & .90 & .80 & .83 & .64 & .42 & .67 \\
\hline \multirow[t]{2}{*}{ SBP } & 1 & .45 & .58 & .85 & .85 & .81 & .77 & .75 \\
\hline & 2 & .62 & .74 & .92 & .92 & .90 & .87 & .86 \\
\hline DBP & 1 & .72 & .80 & .78 & .87 & .84 & .85 & .86 \\
\hline \multirow{2}{*}{ TPR } & 2 & .83 & .89 & .87 & .93 & .91 & .92 & .92 \\
\hline & $\begin{array}{l}1 \\
2\end{array}$ & $\begin{array}{r}.14 \\
85\end{array}$ & 87 & $.89(.88)$ & $\begin{array}{l}.02 \\
.90\end{array}$ & $\begin{array}{l}.87(.85) \\
90(.92)\end{array}$ & $\begin{array}{l}.75(.73) \\
86(84)\end{array}$ & $\begin{array}{r}.81 \\
90\end{array}$ \\
\hline
\end{tabular}

Note: $G^{*}$ is given in parentheses only when it differs from $G$.

${ }^{a} \mathrm{HR}=$ heart rate; $\dot{Q}=$ cardiac output $\mathrm{SV}=$ stroke volume; $\mathrm{HI}=$ Heather Index; PEP $/ \mathrm{LVET}=$ preejection period/left ventricular ejection time; $\mathrm{SBP}=$ systolic blood pressure; $\mathrm{DBP}=$ diastolic blood pressure; $\mathrm{TPR}=$ total peripheral resistance.

The PEP/LVET responses did not differ from baseline, whereas the $\mathrm{HI}$ responses decreased. The HI data conform with Stratton et al.'s (1983) finding of a decrease in contractility during the hand immersion cold pressor test as reflected by decreased ejection fraction. With the exception of $\mathrm{HR}$, evaluation of the general response patterns evoked by forehead stimulation, hand immersion, and foot immersion cold pressor tests indicate that the three sites produce essentially equivalent responses despite the involvement of different neuronal pathways.

Taken together, the data support the view (Abboud \& Eckstein, 1966; Schneiderman \& McCabe, 1989) that the cold pressor test, in its various formats, represents an alpha-adrenergic challenge. The prominent role of TPR in maintaining BP during the task relative to $S V$ and $\dot{Q}$ is underscored when the percentage of variance explained by the task is considered. Seventeen percent of the variance in TPR compared with $\leq \mathbf{2 \%}$ of the variance in $\mathrm{SV}$ and $\dot{Q}$ is explained by the task. In contrast to the suggestion of possible beta-adrenergic influences (e.g., Lovallo, 1975; Sherwood et al., 1986; Victor, Leimbach, Seals, Wallin, \& Mark, 1987), the present findings lend little to support this hypothesis. Neither PEP/LVET nor HI increased, and SV decreased. Although HR increased during the foot and hand cold pressor conditions, the most likely cause for the increase in $\mathrm{HR}$ was a decrease in vagal restraint.

Our second goal was to determine the stability of the responses evoked by the tasks. The reliability analyses indicate that the three cold pressor tests produce stable responses over a 2-week interval with very little, if any, attenuation. When comparisons are made among studies examining stability of forehead stimulation (Durel et al., 1993; Peckerman et al., 1991; Saab et al., 1992), hand immersion (Arena et al., 1983; Fahrenberg et al., 1987; McKinney et al., 1985; Myrtek, 1985), and foot immersion (Allen et al., 1987; Durel et al., 1993; Lacey \& Lacey, 1962), it is clear that the coefficients derived from the present data are comparable to or exceed those obtained for shorter as well as longer test-retest intervals. This is particularly noteworthy for the deltas because they are typically less reliable. Furthermore, the strength of our data lies in the comprehensive view of reliability provided for all three versions of the task.

Efforts in the present study were directed at maximizing conditions that would enhance reliability on retest. These methodological conditions included standardizing the test-retest interval, appointment times, experimenters, electrode application, and posture. ${ }^{6}$ Furthermore, the instructions were carefully scripted and adhered to for both sessions so that procedures were virtually identical. All of these factors appear to have contributed to the high reproducibility of the cold pressor-evoked responses. Although attention has been given to these details in recent reports with impedance cardiography (Kasprowicz, Manuck, Malkoff, \& Krantz, 1990; Saab et al., 1993), with the exception of the test-retest interval, most studies evaluating the stability of the cold pressor test have not included information about these factors.

The reliabilities were generally comparable across the three conditions, except for $\dot{Q}$ and SV, where the foot condition produced the most stable responses $(z=1.96, p<.05)$. These parameters, however, are the least important in terms of characterizing the responses to the cold pressor test. Relative to the other parameters measured in the present study, PEP/LVET across all three conditions was the least stable. Because ours is the first study to report the reproducibility of PEP/LVET on the cold

${ }^{6}$ The semireclined posture appears to account for the improved reliabilities for forehead stimulation relative to results of our previous work. Our earlier studies examined stability of forehead stimulation when subjects sat upright (Durel et al., 1993; Saab et al., 1992), which made it difficult to apply the icepack in a consistent manner. 
pressor test, it is unclear whether this relationship is specific to the present study. However, our reliability data indicate that all three tasks elicit stable measures of the critical parameters: SBP, DBP, TPR, and HR.

The present data support the position that the three versions of the cold pressor test represent stable cardiovascular vasoconstrictor stressors. Together with recent epidemiological findings (e.g., Menkes et al., 1989), the evidence for the temporal stability of the cold pressor test underscores the potential value of this test in prospective as well as cross-sectional studies of hypertensive risk status. Future work, however, will be required to determine the long-term stability of the cold pressor test, particularly with respect to TPR, $\dot{Q}, \mathrm{SV}$, and systolic time intervals.

\section{REFERENCES}

Abboud, F. M., \& Eckstein, J. W. (1966). Active reflex vasodilatation in man. Federation Proceedings, 25, 1611-1617.

Allen, M. T., \& Crowell, M. D. (1989). Patterns of autonomic response during laboratory stressors. Psychophysiology, 26, 603-614.

Allen, M. T., Sherwood, A., Obrist, P. A., Crowell, M. D., \& Grange, L. A. (1987). Stability of cardiovascular reactivity to laboratory stressors: A $2 \frac{1}{2}$ yr follow-up. Journal of Psychosomatic Research, $31,639-645$.

Anderson, N. B., Lane, J. D., Muranaka, M., Williams, R. B., \& Houseworth, S. J. (1988). Racial differences in blood pressure and forearm vascular responses to the cold face stimulus. Psychosomatic Medicine, 50, 57-63.

Arena, J. G., Blanchard, E. B., Andrasik, F., Cotch, P. A., \& Myers, P. E. (1983). Reliability of psychophysiological assessment. Behavior Research and Therapy, 21, 447-460.

Armstrong, H. R., \& Rafferty, J. A. (1950). Cold pressor test followup study for seven years on 166 officers. American Heart Journal, $39,484-490$.

Cronbach, L. J., Glaser, G. C., Nanda, H., \& Rajaratnam, N. (1972). The dependability of behavioral measurements. New York: Wiley.

Durel, L. A., Kus, L. A., Anderson, N. B., McNeilly, M., Llabre, M. M., Spitzer, S., Saab, P. G., Efland, J., Williams, R., \& Schneiderman, N. (1993). Patterns and stability of cardiovascular responses to variations of the cold pressor test. Psychophysiology, 30, 39-46.

Eich, R. H., \& Jacobsen, E. C. (1967). Vascular reactivity in medical students followed for $10 \mathrm{yr}$. Journal of Chronic Diseases, 20 , 583-592.

Fahrenberg, J., Schneider, H. J., \& Safian, P. (1987). Psychophysiological assessments in a repeated-measurement design extending over a one-year interval: Trends and stability. Biological Psychology, 24, 49-66.

Faulstich, M. E., Williamson, D. A., McKenzie, S. J., Duchmann, E. G., Hutchinson, K. M., \& Blouin, D. C. (1986). Temporal stability of psychophysiological responding: A comparative analysis of mental and physical stressors. International Journal of Neuroscience, 30 , 65-72.

Garwood, M., Engel, B. T., \& Capriotti, R. (1982). Autonomic nervous system function and aging: Response specificity. Psychophysiology, 19, 378-385.

Guyton, A. C. (1981). Textbook of medical physiology. Philadelphia: Saunders.

Harlan, W. R., Jr., Osborne, R. K., \& Graybiel, A. (1964). Prognostic value of the cold pressor test and the basal blood pressure: Based on an eighteen-year follow-up study. American Journal of Cardiology, 13, 683-687.

Hays, W. L. (1988). Statistics for the social sciences (4th ed.). New York: Holt, Rinehart \& Winston.

Hines, E. A., Jr. (1940). The significance of vascular hyperreaction as measured by the cold-pressor test. The American Heart Journal, 19, 408-416.

Hines, E. A., Jr., \& Brown, G. E. (1936). The cold pressor test for measuring the reactibility of the blood pressure: Data concerning 571 normal and hypertensive subjects. American Heart Journal, 11, 1-9.

Kasprowicz, A. L., Manuck, S. B., Malkoff, S. B., \& Krantz, D. S. (1990). Individual differences in behaviorally evoked cardiovascular response: Temporal stability and hemodynamic patterning. Psychophysiology, 27, 605-619.

Keys, A., Taylor, H., Blackburn, H., Brozek, J., Anderson, J., \& Simonson, E. (1971). Mortality and coronary heart disease among men studied for 23 years. Archives of Internal Medicine, 128, 201-214.

Khurana, R. K., Watabiki, S., Hebel, J. R., Toro, R., \& Nelson, E.
(1980). Cold face test in the assessment of trigeminal-brainstem-vagal function in humans. Annals of Neurology, 7, 144-149.

Kubicek, W. G., Witsoe, D. A., Patterson, R. P., \& From, A. H. L. (1969). Development and evaluation of an impedance cardiographic system to measure cardiac output and other cardiac parameters (NASA-CR-101965). Houston: National Aeronautic and Space Administration.

Lacey, J. I., \& Lacey, B. C. (1962). The law of initial value in the longitudinal study of autonomic constitution: Reproducibility of autonomic response patterns over a four-year interval. Annals of the New York Academy of Science, 98, 1257-1290.

Light, K. C., Obrist, P. A., Sherwood, A., James, S. A., \& Strogatz, D. S. (1987). Effects of race and marginally elevated blood pressure on responses to stress. Hypertension, 10, 555-563.

Llabre, M. M., Ironson, G. H., Spitzer, S. B., Gellman, M. D., Weidler, D. J., \& Schneiderman, N. (1988). How many blood pressure measurements are enough?: An application of generalizability theory to the study of blood pressure reliability. Psychophysiology, 25, 97-106.

Lovallo, W. (1975). The cold pressor test and autonomic function: A review and integration. Psychophysiology, 12, 268-282.

McKinney, M. E., Miner, M. H., Rüddel, H., Mcllvain, H. E., Witte, H., Buell, J. C., \& Eliot, R. S. (1985). The standardized mental stress test protocol: Test-retest reliability and comparison with ambulatory blood pressure monitoring. Psychophysiology, 22, 453-463.

Menkes, M. S., Matthews, K. A., Krantz, D. S., Lundberg, U., Mead, L. A., Qaqish, B., Liang, K.-Y., Thomas, C. B., \& Pearson, T. A. (1989). Cardiovascular reactivity to the cold pressor test as a predictor of hypertension. Hypertension, 14, 524-530.

Musante, L., Treiber, F. A., Strong, W. B., \& Levy, M. (1990). Family history of hypertension and cardiovascular reactivity to forehead cold stimulation in black male children. Journal of Psychosomatic Research, 34, 111-116.

Myrtek, M. (1985). Adaptation effects and the stability of physiological responses to repeated testing. In A. Steptoe, H. Rüddel, \& H. Neus (Eds.), Clinical and methodological issues in cardiovascular psychophysiology (pp. 93-106). Berlin: Springer-Verlag.

Nagel, J. H., Shyu, L. Y., Reddy, S. P., Hurwitz, B. E., McCabe, P. M., \& Schneiderman, N. (1989). New signal processing techniques for improved precision of noninvasive impedance cardiography. Annals of Biomedical Engineering, 17, 517-534.

Peckerman, A., Saab, P. G., McCabe, P. M., Skyler, J. S., Winters, R. W., Llabre, M. M., \& Schneiderman, N. (1991). Blood pressure reactivity and perception of pain during the forehead cold pressor test. Psychophysiology, 28, 485-495.

Saab, P. G., Llabre, M. M., Hurwitz, B. E., Frame, C. A., Reineke, L. J., Fins, A. I., McCalla, J., Cieply, L. K., \& Schneiderman, N. (1992). Myocardial and peripheral vascular responses to behavioral challenges and their stability in black and white Americans. Psychophysiology, 29, 384-397.

Saab, P. G., Tischenkel, N., Spitzer, S. B., Gellman, M. D., DeCarlo Pasin, R., \& Schneiderman, N. (1991). Race and blood pressure status influences cardiovascular responses to challenge. Journal of $\mathrm{Hy}$ pertension, 9, 249-258.

Schneiderman, N., \& McCabe, P. M. (1989). Psychophysiologic strategies in laboratory research. In N. Schneiderman, S. M. Weiss, \& P. G. Kaufmann (Eds.), Handbook of research methods in cardiovascular behavioral medicine (pp. 349-364). New York: Plenum.

Sherwood, A., Allen, M. T., Obrist, P. A., \& Langer, A. W. (1986). Evaluation of beta-adrenergic influences on cardiovascular and metabolic adjustments to physical and psychological stress. Psychophysiology, $23,89-104$. 
Stratton, J. R., Halter, J. B., Hallstrom, A. P., Caldwell, J. H., \& Ritchie, J. L. (1983). Comparative plasma catecholamine and hemodynamic responses to handgrip, cold pressor and supine bicycle exercise testing in normal subjects. Journal of the American College of Cardiology, 2, 93-104.

Thacker, E. A. (1940). A comparative study of normal and abnormal blood pressures among university students, including cold-pressor test. American Heart Journal, 20, 89-97.

Tischenkel, N. J, Saab, P. G., Schneiderman, N., Nelesen, R. A., DeCarlo Pasin, R., Goldstein, D. A., Spitzer, S. B., Woo-Ming, R., \& Weidler, D. J. (1989). Cardiovascular and neurohumoral responses to behavioral challenge as a function of race and sex. Health Psychology, 8, 503-524.

Treiber, F. A., Musante, L., Braden, D., Arensman, F., Strong, W. B. Levy, M., \& Leverett, S. (1990). Racial differences in hemodynamic responses to the cold face stimulus in children and adults. Psychosomatic Medicine, 52, 286-296.

Van Egeren, L. F., \& Sparrow, A. W. (1989). Laboratory stress testing to assess real-life cardiovascular reactivity. Psychosomatic Medicine, $51,1-9$.

Victor, R. G., Leimbach, W. N., Jr., Seals, D. R., Wallin, B. G., \& Mark, A. L. (1987). Effects of the cold pressor test on muscle sympathetic nerve activity in humans. Hypertension, 9, 429-436.

Wood, D. L., Sheps, S. G., Elveback, L. R., \& Schirger, A. (1984). Cold pressor test as a predictor of hypertension. Hypertension, 6, 301-306.

(Recerved November 27, 1991; Accepted July 6, 1992) 